\title{
Hydrophilins from distant organisms can protect enzymatic activities from water limitation effects in vitro
}

\author{
JOSE L. REYES ${ }^{2}$, MARIA-J. RODRIGO ${ }^{1, *}$, JOSE M. COLMENERO-FLORES $^{2, \dagger}$, JOSE-V. GIL ${ }^{1, *}$, \\ ADRIANA GARAY-ARROYO ${ }^{2}$, FRANCISCO CAMPOS $^{2}$, FRANCESCO SALAMINI $^{1}$, DOROTHEA BARTELS $^{1, \S}$ \& \\ ALEJANDRA A. COVARRUBIAS ${ }^{2}$
}

${ }^{1}$ Max Planck Institute für Zuchtungsforschung, Carl von Linne Weg 10, D-50829 Cologne, Germany and ${ }^{2}$ Universidad Nacional Autonoma de Mexico, Department Plant Molecular Biology, Institute of Biotechnology, Apdo Postal 510-3, Cuernavaca 62250, Morelos, Mexico

\begin{abstract}
Hydrophilins are a wide group of proteins whose defining characteristics are high hydrophilicity index $(>1.0)$ and high glycine content $(>6 \%)$. The transcripts of most hydrophilins accumulate in response to water deficit in organisms such as plants, fungi and bacteria. In plants, most of the known Late Embryogenesis Abundant (LEA) proteins belong to this group (Garay-Arroyo et al., Journal of Biological Chemistry 275, 5668-5674, 2000). To gain insight into the function of hydrophilins, an in vitro assay was developed in which the enzymes malate dehydrogenase (MDH) or lactate dehydrogenase (LDH) are subjected to controlled partial water removal. Subtle changes in conformation during partial water removal were detected using 1anilinonaphtalene-8-sulphonate (ANS), a fluorescent probe, whose emission at $460 \mathrm{~nm}$ increases when bound to hydrophobic groups. The results show that water limitation conditions imposed in this in vitro assay induce changes in MDH or LDH protein structures, which correlate with enzyme inactivation. It is also shown that plant, fungal and bacterial hydrophilins are able to protect enzymatic activities from water-loss effects in this in vitro system, in a wide range of water potentials. In addition, the data in this work indicate that the presence of hydrophilins also avoids the MDH and LDH conformational modifications caused during the assay. These results show that hydrophilins are able to protect enzymatic activities from inactivation due to in
\end{abstract}

Correspondence: Alejandra A. Covarrubias. Fax: 52-777-313-9988; e-mail: crobles@ibt.unam.mx

* Present address: Instituto de Agroquimica y Tecnologia de Alimentos (CSIC), Apartado de Correos 73, 46100 Burjassot, Valencia, Spain.

${ }^{\dagger}$ Present address: Centro de Genomica, Instituto Valenciano de Investigaciones Agrarias, Ctra. Moncada-Naquera, Km. 5. 46113Moncada, Valencia. Spain.

${ }^{\S}$ Present address: Botanisches Institut University of Bonn, Kirschallee 1, D-53115 Bonn, Germany. vitro partial water limitation and thus suggest a function for these proteins in vivo.

Key-words: dehydrins; enzyme protection; hydrophilic proteins; hydrophilins; LEA proteins; protein stabilization; water deficit.

\section{INTRODUCTION}

Water stress may affect all types of organisms at some stage of their life cycle. Hence, they have developed a number of strategies to cope with water deficit, including changes in enzyme activities and gene expression patterns. In plants, hydrophilic proteins, known as Late Embryogenesis Abundant (LEA) proteins accumulate to high levels during the last stage of seed formation (when a natural desiccation of the seed tissues takes place) and during periods of water deficit in vegetative organs, suggesting a protective role of these proteins during water limitation (Bray 1997). LEA proteins have been grouped into at least six families on the basis of sequence similarity (Ingram \& Bartels 1996; Colmenero-Flores et al. 1997, 1999). Although significant similarity has not been detected between the members of the different classes, a unifying and outstanding feature of these proteins is their high hydrophilicity and high percentage of glycine residues (Baker, Steele \& Dure 1988; Dure 1993).

We have previously shown that most LEA proteins are comprised in a more widespread group, which we call 'hydrophilins'. Their defining characteristics are a glycine content $>6 \%$ and a hydrophilicity index $>1$ (Anchordoguy \& Carpenter 1996). By database searching, we showed that this criterion selects most known LEA proteins, as well as additional proteins from different taxons, suggesting that hydrophilins represent a functionally conserved adaptation to osmotic stress (Garay-Arroyo et al. 2000). Consistent with this idea, we found that within the genomes of Escherichia coli and Saccharomyces cerevisiae, the 5 and 12 proteins, respectively, that meet our criteria have transcripts that accumulate in response to osmotic stress (Garay- 
Arroyo et al. 2000; Posas et al. 2000; Yale \& Bohnert 2001; Comadurán, G., unpublished results).

Although the functional role of hydrophilins remains speculative, there is evidence supporting their participation in acclimation and/or in the adaptive response to stress. In the case of some plant hydrophilins (LEA proteins), their ectopic expression in plants and yeast confers tolerance to water-deficit conditions (Imai et al. 1996; Xu et al. 1996; Swire-Clark \& Marcotte 1999; Zhang et al. 2000), and their presence has been associated with chilling tolerance (Danyluk et al. 1998; Ismail, Hall \& Close 1999; Rinne et al. 1999). Furthermore, deletion of the RMF hydrophilin gene of $E$. coli results in an osmosensitive phenotype (Garay-Arroyo et al. 2000).

To gain insight into the function of hydrophilins, we developed an in vitro partial water loss assay where the activity of malate dehydrogenase (MDH) and lactate dehydrogenase $(\mathrm{LDH})$ is measured in the presence or absence of a putative protecting protein. These enzymes were chosen as models to test enzyme inactivation during partial water removal because of their sensitivity to different stress conditions such as heat, freeze-thaw cycles and lyophilization (Carpenter, Prestrelski \& Arakawa 1993; Dong et al. 1995; Anchordoguy \& Carpenter 1996), as well as the ease to assay their enzymatic activity. Importantly, in this assay, the amount of water remaining after controlled evaporation is significantly larger than that attained during protein lyophilization or complete dehydration. However, the inhibitory effects of such treatment on enzyme activity were self-evident. Given that MDH and $\mathrm{LDH}$ activities were sensitive to different degrees of in vitro water removal, we were able to test the putative protective role of hydrophilins. To this end, we selected LEA proteins from different groups: dehydrins DSP16 and ERD10 (group 2), AtLEA76 (group 3), AtD113 (group 4) and PvLEA18 (group 6) (Ingram \& Bartels 1996; Colmenero-Flores et al. 1997). In addition, we included hydrophilins from E. coli, YCIG, and from S. cerevisiae, Sip18, and tested the sensitivity of $\mathrm{MDH}$ and $\mathrm{LDH}$ activity to partial water loss (low water potentials) in the presence or absence of a putative protecting protein.

Our results show that, under the conditions tested, all hydrophilins, except PvLEA18, are more efficient protectants of enzyme activities during in vitro partial water loss than other unrelated proteins (RNAse A, $\beta$ Lactoglobulin and $\alpha$ Crystallin, a molecular chaperone). We also show that inactivation of $\mathrm{MDH}$ and $\mathrm{LDH}$ due to in vitro water removal correlates with changes in enzyme exposure of hydrophobic surfaces, as determined by 1-anilinonaphtalene-8-sulphonate (ANS) fluorescence assays. Furthermore, such changes are partially prevented by addition of DSP16 or SIP18. The overall results indicate that hydrophilins protect enzyme activities in vitro by a mechanism that prevents modification of the enzyme structure, which is affected upon partial water removal in the absence of a hydrophilin. These data show for the first time a protective in vitro function/activity for hydrophilins (LEA proteins included) against water limitation effects.

\section{MATERIALS AND METHODS}

\section{Proteins and other chemicals}

Bovine serum albumin (BSA) (initial fraction obtained by cold alcohol precipitation, globulin free), $\alpha$ Crystallin from bovine eye lens, $\beta$ Lactoglobulin from bovine milk, and trehalose were purchased from Sigma (St Louis, MO, USA). $\mathrm{MDH}$ (EC 1.1.1.37) from pig heart (mitochondrial) and LDH (EC 1.1.1.27) from hog muscle were purchased from Boehringer, (Mannheim, Germany). The commercial preparations of $\mathrm{MDH}$ and $\mathrm{LDH}$ were supplied in $50 \%$ glycerol, and their purity was confirmed by sodium dodecyl sulphate (SDS)-polyacrylamide gel electrophoresis (PAGE). The hydrophilins used were the dehydrins (group 2) DSP16 from Craterostigma plantagineum and ERD10 from Arabidopsis thaliana; AtLEA76, a group 3 LEA protein from $A$. thaliana; AtD113, a group 4 LEA protein from $A$. thaliana; PvLEA18, a group 6 LEA protein from Phaseolus vulgaris. In addition, we have included hydrophilins from E. coli, YCIG, and from S. cerevisiae, Sip18. The recombinant proteins PvLEA18, Sip18, YCIG, and DSP16 were expressed as soluble polypeptides containing an N-terminal His-tag carried in suitable pQE vectors (Qiagen, Hilden, Germany) and affinity purified on Ni-NTA Agarose resin (Qiagen) under native conditions. LEA proteins ERD10, D113 and LEA76 were expressed in E. coli as untagged proteins, and purified by boiling of a cell extract (Jepson \& Close 1995) and subsequent ammonium sulphate fractionation followed by ionic exchange chromatography and dialysis. All purified proteins (up to $95-98 \%$ purity) were re-suspended in $150 \mathrm{~mm}$ potassium phosphate buffer, $\mathrm{pH}$ 7.5. Protein concentrations were determined by the Bradford protein assay and verified by SDS-PAGE.

\section{Partial water loss assays}

$\mathrm{MDH}$ and LDH were used to test the effect of additives on their activity upon exposure to in vitro partial water loss. Experiments were performed in Eppendorf tubes to avoid protein adsorption to glass. For MDH, the enzyme and the additive were dissolved in $50 \mathrm{~mm}$ potassium phosphate buffer, pH 7.2. For LDH, experiments were carried out in $25 \mathrm{mM}$ Tris- $\mathrm{HCl}, \mathrm{pH}$ 7.5. In both cases the final (monomer) enzyme concentration was $250 \mathrm{nM}$ corresponding to $10 \mu \mathrm{g} \mathrm{mL} L^{-1}$ of $\mathrm{MDH}$ and $8.3 \mu \mathrm{g} \mathrm{mL}^{-1}$ of $\mathrm{LDH}$. The choice of enzyme concentration was based on the following considerations: (1) LDH concentrations higher than $10 \mu \mathrm{g}$ $\mathrm{mL}^{-1}$ may induce self-protection (Carpenter et al. 1993; Anchordoguy \& Carpenter 1996; Miller, Anderson \& de Pablo 1998), and (2) stabilizers present in the commercial preparation may interfere with the assay. We therefore chose the lowest concentration compatible with the sensitivity of the enzyme assay.

Molar ratios of hydrophilin to enzyme were established as the minimum molar ratio at which a specific protein preserved full enzyme activity at a fixed dehydration level (99.5\% water loss for $\mathrm{MDH}$ and $98.5 \%$ water loss for 
$\mathrm{LDH})$. The proteins tested in the MDH assays were added at a monomer concentration of $625 \mathrm{nM}$, corresponding to a protein:enzyme molar ratio of $2.5: 1$. For LDH assays, proteins tested were at $250 \mathrm{nM}$ (monomer) and the molar ratio of protein : enzyme was $1: 1$. Aliquots $(75 \mu \mathrm{L})$ of the mixtures were placed in a Speed-Vac concentrator (Savant Instruments, Holbrook, NY, USA) and water evaporated for various times to achieve the degree of water loss required. Evaporative cooling prevented heat denaturation of the sample, so freezing could be dispensed during vacuum-drying. The percentage of partial water loss was defined as the amount of water evaporated from the samples, determined by weighting the sample tubes in an analytical balance (Sartorius, Goettingen, Germany) before and after protein mixtures were added and after the evaporation period. To have a reference of the water status of the solutions in these assay, the osmolality of some samples was determined using a cryoscopic osmometer, Osmomat 030 (Gonotec, Berlin, Germany). An osmolality of $0.116 \mathrm{~mol} \mathrm{~kg}^{-1}$ (-2.83 bars) corresponded to a water loss of approximately $50 \% ; \quad 0.228 \mathrm{~mol} \mathrm{~kg}^{-1} \quad$ (-5.07 bars) to approximately $75 \%$ of water loss; $0.398 \mathrm{~mol} \mathrm{~kg}^{-1}$ ( -9.71 bars) to a water loss of approximately $87.5 \%$; $0.765 \mathrm{~mol} \mathrm{~kg}^{-1}$ (-21.41 bars) was equivalent to approximately $93.75 \%$ water loss; and $1241 \mathrm{~mol} \mathrm{~kg}^{-1}$ (-30.24 bars) corresponded to a water loss of $96.87 \%$.

The partially evaporated samples were restored to the initial weight with water either immediately or after $3 \mathrm{~d}$ of incubation at $25^{\circ} \mathrm{C}$. After water addition, samples were kept on ice, and care was taken to ensure that all solutes were completely re-suspended before determining enzyme activity. The initial activity was determined on aliquots that had been kept at $4{ }^{\circ} \mathrm{C}$ until all samples were ready to assay.

To evaluate the aggregation of MDH during partial water loss, $0.4 \mathrm{~mL}$ aliquots of $\mathrm{MDH}$ at the concentration of $630 \mathrm{nM}$ monomer (the minimum concentration required for aggregation) in $50 \mathrm{~mm}$ potassium phosphate buffer, $\mathrm{pH} 7.2$ were pipetted into Eppendorf tubes and water evaporated in a Speed-Vac concentrator. After partial water removal, samples were restored to the initial volume with water, and the degree of aggregation of MDH was determined by measuring the absorption due to increased turbidity from light scattering at $360 \mathrm{~nm}$ in a Beckman DU 600 spectrophotometer (Beckman-Coulter, Fullerton, CA, USA), as previously described (Lee 1995).

\section{Enzyme activity measurements}

$\mathrm{MDH}$ and $\mathrm{LDH}$ enzymatic activities were determined using aliquots of 8 and $15 \mu \mathrm{L}$, respectively, in a final volume of $600 \mu \mathrm{L}$ of the reaction assay buffer. $\mathrm{MDH}$ enzymatic activity was assayed in $150 \mathrm{~mm}$ potassium phosphate buffer pH 7.5 containing $0.2 \mathrm{~mm}$ oxalacetate (Sigma) and $0.2 \mathrm{~mm}$ $\mathrm{NADH}$ (Boehringer). For $\mathrm{LDH}$, the assay buffer was $25 \mathrm{mM}$ Tris- $\mathrm{HCl} \mathrm{pH} 7.5,100 \mathrm{mM} \mathrm{KCl}$ containing $2 \mathrm{~mm}$ pyruvate (Sigma) and $0.15 \mathrm{~mm} \mathrm{NADH} \mathrm{(Boehringer).} \mathrm{MDH} \mathrm{and}$ $\mathrm{LDH}$ activities were monitored as the rate of decrease in absorbance at $340 \mathrm{~nm}$ for 1 min due to the conversion of $\mathrm{NADH}$ into NAD at $25^{\circ} \mathrm{C}$.

\section{ANS fluorescence assays}

Changes in fluorescence due to binding of the fluorescent probe 1-anilinonaphtalene-8-sulphonate (ANS, Sigma) were measured using a DyNA Quant 200 instrument (Amersham Pharmacia Biotech, Piscataway, NJ, USA) according to manufacturer directions (supplement 5 to users manual). LDH or MDH were incubated in $25 \mathrm{~mm}$ Tris- $\mathrm{HCl}, \mathrm{pH}$ 7.5. The final monomer concentration was $500 \mathrm{nM}$ for both enzymes, instead of $250 \mathrm{nM}$ as for the partial water loss assays. Hydrophilins were added at the same ratio as in the partial water loss assays. ANS was added to $5 \mu \mathrm{M}$ final concentration in all cases. For determination of fluorescence, the same procedure described above for the partial water loss assays was used, and ANS was added immediately after the initial volume was restored with water. For heat-denaturation experiments, samples containing $\mathrm{LDH}$ or $\mathrm{MDH}$ were incubated for $40 \mathrm{~min}$ at $55^{\circ} \mathrm{C}$, placed on ice for $2 \mathrm{~min}$ and ANS added immediately after.

\section{Protein-protein cross-linking}

For cross-linking of hydrophilins to $\mathrm{LDH}$ or MDH we utilized Tris-bipyridylruthenium(II) di-cation $\left(\mathrm{Ru}(\mathrm{II}) \mathrm{bpy}_{3}{ }^{2+}\right.$, Sigma) using the method described before with minor modifications (Fancy \& Kodadek 1999). Briefly, after the standard partial water removal procedure (without rehydration), the protein mixture was brought to $10 \mu \mathrm{L}$ containing $1.25 \mathrm{mM} \mathrm{Ru}(\mathrm{II}) \mathrm{bpy}_{3}{ }^{2+}, 2.5 \mathrm{mM}$ ammonium persulphate and it was flashed for $5 \mathrm{~s}$ through a $3 \mathrm{~cm}$ water-filter using a white light bulb as source $(75 \mathrm{~W})$. Samples were subsequently quenched with an equal volume of $2 \times$ Laemmli sample buffer containing $4 \%$ SDS and $10 \% \beta$-mercaptoethanol, and resolved by SDS-PAGE. Protein bands were visualized by Western blot using anti-His tag antibody (Qiagen). To visualize LDH and MDH, enzymes were previously labelled with biotin (Boehringer) as indicated by the manufacturer, and membranes were developed with streptavidin-coupled horseradish peroxidase (Zymed, South San Francisco, CA, USA). As a reference, we also used two of the proteins that do not show protective properties in the water loss in vitro assays such as RNAse A and lysozyme.

All experimental data reported are means of, at least, three independent measurements with standard errors. Where no error bars are shown, the size of the symbol indicates deviations.

\section{RESULTS}

\section{MDH and LDH activities are sensitive to controlled in vitro water loss}

The rate of inactivation of the MDH and $\mathrm{LDH}$ activities during controlled water loss was determined after immedi- 


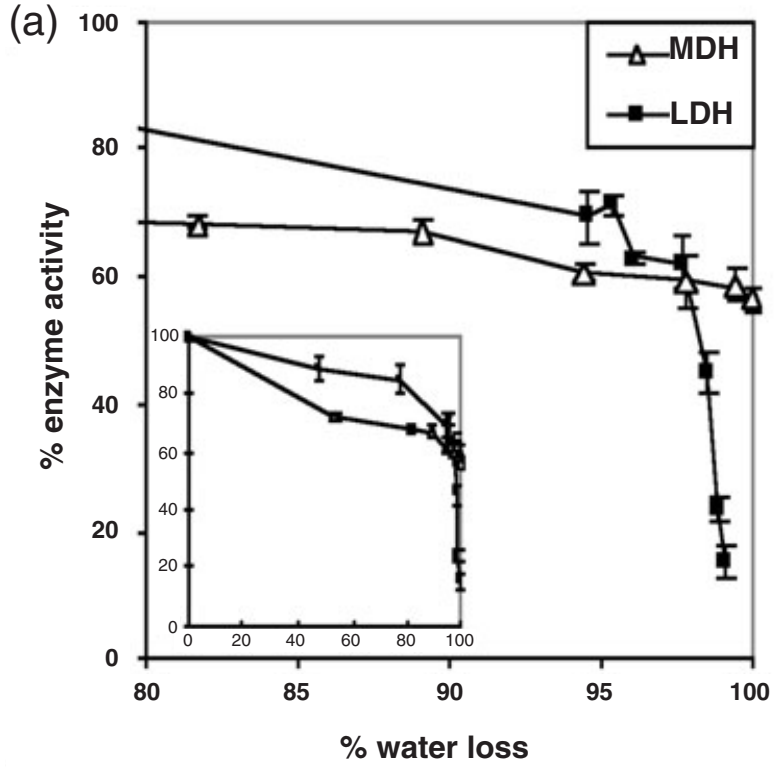

(b)

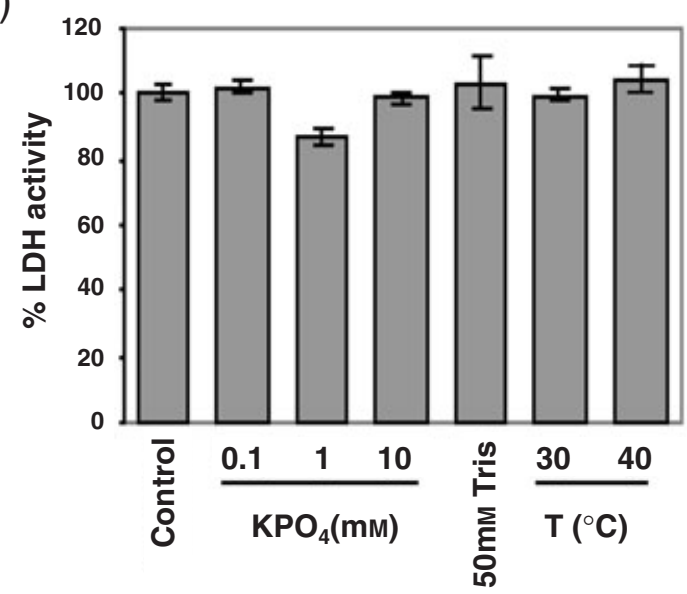

Figure 1. MDH and LDH enzyme activities decrease upon partial water loss. (a) After different degrees of partial water loss, $\operatorname{MDH}(\triangle)$ and LDH (ם) enzyme samples were immediately rehydrated and their remaining activity determined. The remaining activity is expressed as a percentage of control. (b) An LDH sample containing $25 \mathrm{~mm}$ Tris was partially dehydrated to $95 \%$ water loss at $25^{\circ} \mathrm{C}$ (Control). Alternatively it contained varying initial concentrations of $\mathrm{KPO}_{4}$ or Tris buffer or incubated at two different temperatures for $1 \mathrm{~h}$ as indicated.

ately restoring the samples to their initial volume. $\mathrm{MDH}$ and LDH activities decreased during this process and the rate of inactivation was different for each enzyme (Fig. 1a, inset). MDH was more sensitive than $\mathrm{LDH}$ to mild water loss treatments. MDH lost about $40 \%$ of its initial activity during the process (Fig. 1a), whereas LDH retained between 70 and $80 \%$ of its initial activity even after $99 \%$ water loss was attained (Fig. 1a). Beyond this point, LDH activity dropped to $10 \%$ whereas $\mathrm{MDH}$ retained about $55 \%$ of its initial activity. When both enzymes were partially dehydrated and kept at $25^{\circ} \mathrm{C}$ for $3 \mathrm{~d}$, their activities showed a larger decrease in the range of water loss tested (15-5\% of its initial activity, data not shown).

Control experiments using different initial concentrations of the ions present in the buffer used in these assays $\left(\mathrm{K}^{+}\right.$, Tris, $\left.\mathrm{PO}_{4}^{-}\right)$were carried out. In the case of $\mathrm{LDH}$, increasing $\mathrm{K}^{+}$and $\mathrm{PO}_{4}^{-}$concentrations as high as 100 -fold, or Tris ${ }^{-}$up to two-fold, did not affect its activity (Fig. 1b). For $\mathrm{MDH}$, increasing $\mathrm{K}^{+}$and $\mathrm{PO}_{4}^{-}$concentrations as high as 20 -fold did not show any negative effects on enzyme activity (data not shown). Although temperature was carefully controlled during the assay, we confirmed that temperatures as high as $40^{\circ} \mathrm{C}$ did not reduced $\mathrm{LDH}$ or $\mathrm{MDH}$ activities (Fig. $1 \mathrm{~b}$ and data not shown). These results indicate that the decrease in enzyme activity observed during partial water loss was not due to the resulting increase in ion concentration or to eventual temperature fluctuations.

\section{Enzyme structural changes during partial water loss}

In order to correlate the loss of enzymatic activity detected during the water loss assay with possible structural modifications, we used two different approaches. Initially, protein unfolding was determined by measuring MDH aggregation in samples that had been subjected to partial water loss to various extents and rehydrated immediately. No aggregation of MDH was detected in a range of water loss (29.2 to $0.6 \%$ of remaining water, approximately -7 to -40 bars) suggesting that no extensive irreversible protein denaturation occurs under these conditions (data not shown). To detect subtle changes in conformation during partial water removal, a different, more sensitive method using ANS, a fluorescent probe, was applied. In water, ANS is essentially non-fluorescent, but its emission at $460 \mathrm{~nm}$ increases when bound to different hydrophobic groups (Suarez-Varela, Sanchez-Macho \& Minones 1992). Thus, if the decrease in LDH or MDH activity during in vitro partial dehydration is the result of structural modifications, ANS would bind differently to the enzyme and change the fluorescent signal of the sample. When LDH or MDH were incubated in the presence of $5 \mu \mathrm{M}$ ANS, low fluorescence levels were detected (no treatment, Table 1). Upon partial water removal treatment, two different stages were observed. Initially, between 90 and $98 \%$ water loss the overall ANS fluorescence was reduced by 20 and $50 \%$ for MDH and LDH, respectively (Table 1). At 99\% water loss, fluorescence returned to levels similar to those of the non-treated samples, and at $99.4 \%$ water loss, fluorescence increased by nearly two-fold in LDH samples. In contrast, ANS autofluorescence did not increase over the initial value, even at $99.5 \%$ water loss. However, when MDH samples with the same water loss levels were further incubated for $3 \mathrm{~d}$ before being rehydrated, ANS fluorescence increased by 1.6-fold (Table 1). Changes in ANS fluorescence due to the conditions imposed by the partial dehydration were compared with those of parallel samples exposed to heat denaturation, in which a substantial unfolding of the enzymes occurs. The exposure of enzyme samples to $55^{\circ} \mathrm{C}$ for $40 \mathrm{~min}$ 


\begin{tabular}{|c|c|c|c|c|}
\hline & \multirow[b]{2}{*}{ Treatment } & \multicolumn{3}{|l|}{ Fold change $^{\mathrm{a}}$} \\
\hline & & No additive ${ }^{\mathrm{b}}$ & $+\mathrm{DSP} 16^{\mathrm{b}}$ & $+\mathrm{SIP} 18^{\mathrm{b}}$ \\
\hline \multirow[t]{7}{*}{ LDH } & None & $1.0 \pm 0.06$ & $0.98 \pm 0.10$ & 1.0 \\
\hline & $93.6 \%$ water loss ${ }^{\mathrm{b}}$ & $0.5 \pm 0.05$ & $0.74 \pm 0.02$ & $1.1 \pm 0.08$ \\
\hline & $95.2 \%$ water loss ${ }^{\mathrm{b}}$ & $0.64 \pm 0.1$ & ND & $0.88 \pm 0.07$ \\
\hline & $96.3 \%$ water loss ${ }^{b}$ & $0.66 \pm 0.07$ & $1.03 \pm 0.14$ & $0.92 \pm 0.14$ \\
\hline & $98.8 \%$ water loss ${ }^{\mathrm{b}}$ & $0.87 \pm 0.03$ & ND & ND \\
\hline & $99.4 \%$ water loss ${ }^{b}$ & $1.80 \pm 0.08$ & $1.7 \pm 0.13$ & ND \\
\hline & $40 \min$ at $55^{\circ} \mathrm{C}^{\mathrm{b}}$ & $2.62 \pm 0.13$ & & \\
\hline \multirow[t]{5}{*}{$\mathrm{MDH}$} & None & $1.0 \pm 0.06$ & & \\
\hline & $96-99.1 \%$ water loss ${ }^{\mathrm{b}}$ & $0.79 \pm 0.08$ & & \\
\hline & $99.3 \%$ water loss ${ }^{\mathrm{b}}$ & $0.96 \pm 0.01$ & & \\
\hline & $99.5 \%$ water loss $3 \mathrm{~d}^{\mathrm{b}}$ & $1.6 \pm 0.08$ & & \\
\hline & $40 \mathrm{~min}$ at $55^{\circ} \mathrm{C}^{\mathrm{b}}$ & $3.1 \pm 0.12$ & & \\
\hline
\end{tabular}

Table 1. ANS fluorescence of LDH during partial water loss

${ }^{\mathrm{a}}$ With respect to the control sample without treatment. ${ }^{\mathrm{b}}$ Mean values of at least three independent measurements. ND, not determined.

resulted in a three-fold increase in ANS fluorescence for both MDH and LDH (Table 1). Accordingly, all observed changes in ANS fluorescence correlated with a decrease in both enzymatic activities (see Fig. 1a).

\section{Different hydrophilins protect enzymatic activities during in vitro partial water loss}

Since MDH and LDH activities are sensitive in the partial water loss assay established, we assessed whether hydrophilins play a protective role under these conditions. As reference, other proteins such as BSA, $\alpha$ Crystallin, RNAse A and $\beta$ Lactoglobulin were also tested. BSA is used as a protein stabilizer in many enzyme activity assays (Chang \& Mahoney 1995) and is generally considered to be a cryoprotectant (Tamiya et al. 1985). $\alpha$ Crystallin is a molecular chaperone, which is able to prevent aggregation of heatlabile proteins (Boyle \& Takemoto 1994; Horwitz 1992). RNAse $\mathrm{A}$ and $\beta$ Lactoglobulin are proteins unrelated to stress but are very stable and have molecular weight similar to the hydrophilins tested here. Using $\mathrm{LDH}$ as a target enzyme in this assay, we first tested two dehydrins, DSP16 and ERD10. At water loss levels up to 98\% (approximately -30.24 bars), BSA recovered $75 \%$ of the enzyme activity, whereas $\alpha$ Crystallin, RNAse A and $\beta$ Lactoglobulin did not show any protective effect (Fig. 2a and data not shown). Under the same conditions, ERD10 and DSP16 showed protection levels that recovered LDH activity between $90 \%$ and $100 \%$ (Fig. 2a). In samples that had reached up to $99 \%$ water loss (approximately -50 bars) and immediately rehydrated, only DSP16 induced full protection of LDH activity. When LEA proteins from groups 3 and 4 (AtLEA76 and AtD113) were tested, protection levels similar to those of ERD10 were observed (compare Fig. 2a \& b). In contrast, a group 6 LEA protein, PvLEA18, did not show any significant effect under the conditions assayed (Fig. 2b). Similar protective effects were observed when $\mathrm{MDH}$ was used as target enzyme (data not shown).
To further analyse the role of other hydrophilins we have extended the analysis to include those from organisms different to plants, namely one from E. coli (YCIG) and another from $S$. cerevisiae (Sip18). These proteins were selected since they possess the highest scores as hydrophilins as defined by Garay-Arroyo et al. (2000). As shown in Fig. 3, YCIG confers significant protection to LDH, up to $99 \%$ of water removal (approximately -50 bars), similar to ERD10 and DSP16. Sip18 confers protection to LDH to the same extent as BSA up to $95 \%$ of water loss (approximately -19 bars), however, between 96 and $99 \%$ of water loss (approximately -20 and -50 bars), Sip18 was a better protector (Fig. 3). When trehalose (25-100 mM), another well-known stabilizer of enzyme activities, was added in this assay, the recovered $\mathrm{LDH}$ activity was similar to that of Sip18 (Fig. 3). In the case of MDH, similar effects were observed (data not shown). For all hydrophilins tested, when water loss was larger than 99\% (>-50 bars), LDH and $\mathrm{MDH}$ activities decreased dramatically in all samples and none of the proteins exerted protection.

Thus, except for PvLEA-18, we observed significant in vitro protection provided by hydrophilins from plant, fungi and bacteria of the activities of two enzymes.

\section{Hydrophilins prevent structural changes in LDH upon partial water loss}

Since hydrophilins showed a positive effect on the enzymatic activity recovered after partial water loss, we asked whether this effect correlated with conformational changes as measured by ANS. To this end we selected two hydrophilins from different organisms, DSP16 and Sip18. When LDH samples were partially dehydrated between 93 and 96\% (approximately -18 and -30 bars) in the presence of DSP16, the fluorescence levels recovered were higher and more similar to those of the untreated samples. At $99.4 \%$ water loss (approximately -59.5 bars), no significant change in fluorescence was observed (Table 1). When Sip18 was 
(a)

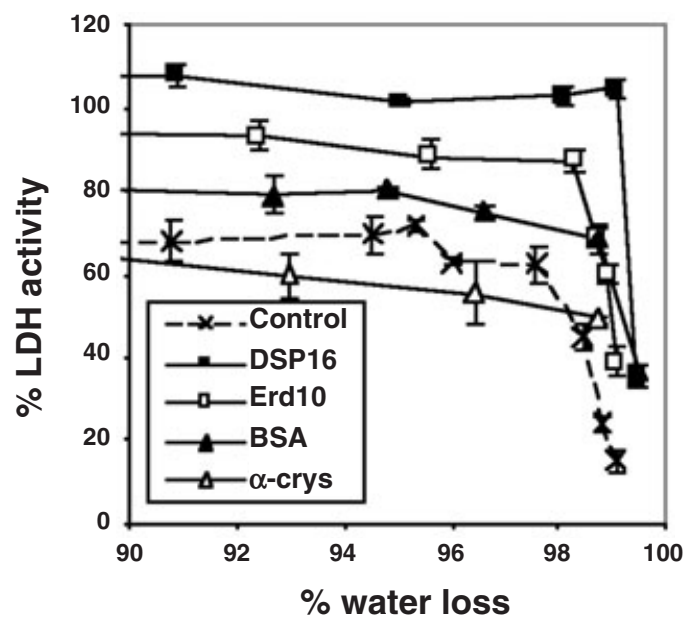

(b)

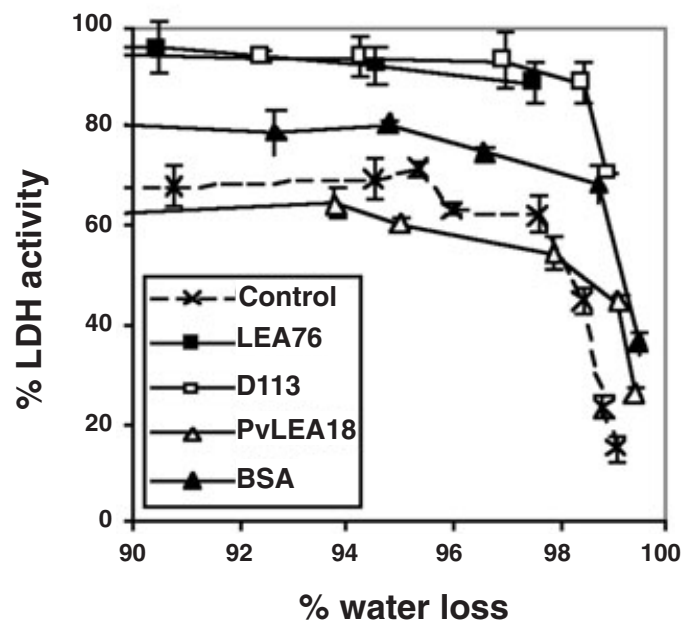

Figure 2. Effect of plant hydrophilins on LDH enzyme activity during partial water loss. LDH samples were subjected to partial water loss, immediately rehydrated and assayed for enzymatic activity. The final concentrations of LDH and proteins were at $250 \mathrm{nM}$ (monomeric form) (the molar ratio of enzyme to protein was $1: 1$ ). In (a) a dashed line indicates enzyme activity without additives, the following symbols indicate the additives: (ם) DSP16; $(\square)$ ERD10; ( $\Delta$ ) BSA; and $(\triangle) \alpha$ Crystallin. In (b) a dashed line indicates enzyme activity without additives: $(\boldsymbol{\square})$ LEA76; $(\square)$ D113; ( $\Delta)$ BSA; and $(\triangle)$ PvLEA18.

used, similar results were obtained (Table 1). In untreated samples the presence of DSP16 or Sip18 does not increase the ANS fluorescence signal above that of LDH alone. In addition, we determined that either hydrophilin alone did not show any fluorescence before or after partial dehydration (data not shown).

\section{Hydrophilins interact with LDH and MDH}

To investigate the mechanism of enzyme protection, we asked whether a hydrophilin-enzyme interaction occurs during the process of gradual water removal. To address this question we used a ruthenium salt $\left(\mathrm{Ru}(\mathrm{II}) \mathrm{bpyy}_{3}{ }^{2+}\right)$ as a

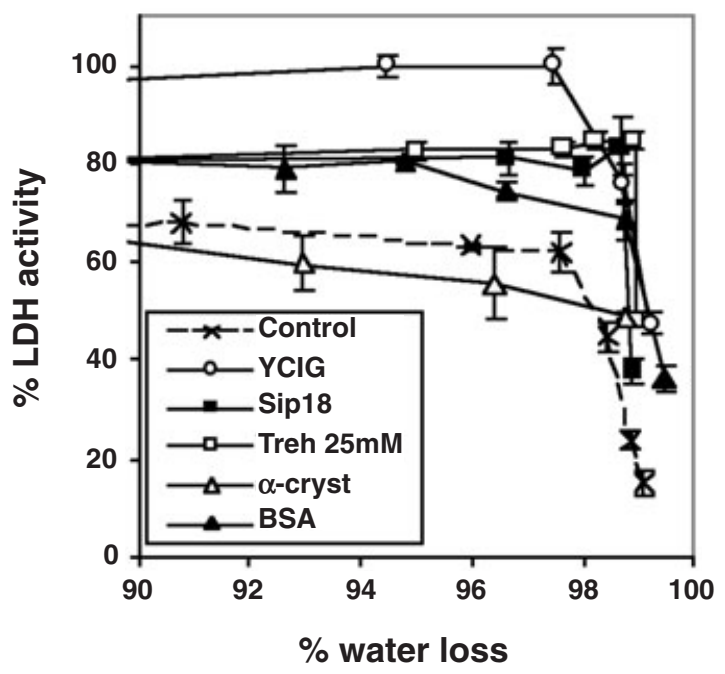

Figure 3. Effect of bacterial and yeast hydrophilins on LDH activity during dehydration. LDH samples were subjected to partial water removal, immediately rehydrated and assayed for enzymatic activity. The final concentrations of LDH and proteins were as in Fig. 2. The dashed line indicates enzyme activity without additives, the following symbols indicate the additives: $(O)$ YCIG;

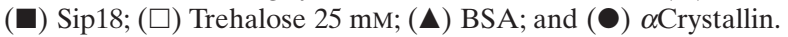

short-range cross-linking agent to detect protein-protein interactions (Fancy \& Kodadek 1999). Samples containing LDH and Sip18 were subjected to partial water removal until $98 \%$ water was lost. At this point the samples were incubated in the presence of $1.25 \mathrm{mM}$ ruthenium salt and flashed with an intense white light. Products of cross-linking were resolved in $12 \%$ SDS-PAGE and visualized by Western blotting using anti-His tag antibody (Fig. 4, lanes

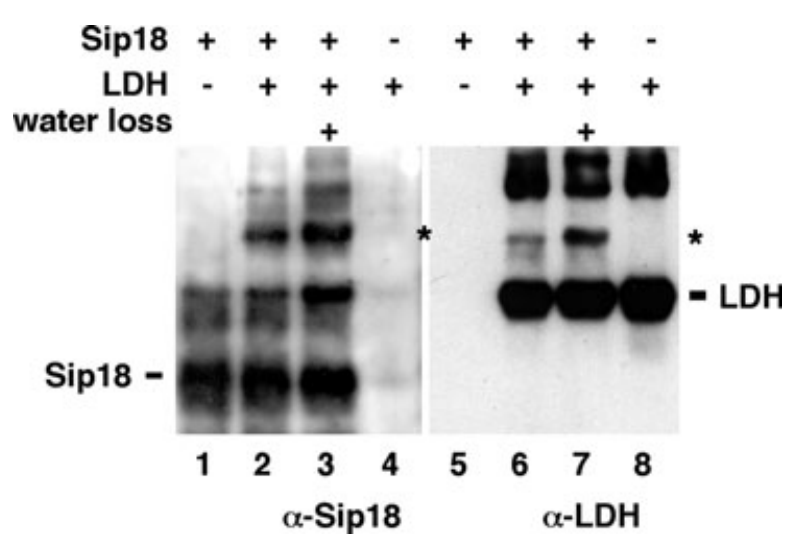

Figure 4. Hydrophilins interact with enzymes during partial water loss. Protein-protein cross-linking reactions using $\mathrm{Ru}(\mathrm{II}) \mathrm{bpy}_{3}{ }^{2+}$ were set with Sip18 alone (lanes 1 and 5), Sip18 and biotinylated LDH (lanes 2, 3, 6 and 7) or biotinylated LDH alone (lanes 4 and 8). LDH was incubated in the presence of Sip18 either as a concentrated mixture (lanes 2 and 6 ) or after $98 \%$ water loss (lanes 3 and7). Cross-linking products were resolved by 12\% SDSPAGE and visualized by Western blot with anti-His tag antibody (lanes 1-4) or with HRP-coupled streptavidin (lanes 5-8). The position of the LDH:Sip18 product is indicated by an asterisk. 
1-4). Incubation of Sip18 alone under cross-linking conditions (lane 1) revealed that the fastest migrating species corresponded to Sip18, whereas the slower migrating bands are generated upon cross-linking of Sip18. Although LDH by itself does not cross-react with anti-His tag antibody (lane 4) a slower migrating species is generated when LDH and Sip18p are incubated together (lanes 2 and 3 , indicated by an asterisk). The signal in this band is weaker when both proteins are incubated without prior treatment (lane 2), or absent when cross-linking is omitted (not shown), but it is enhanced upon partial water loss and cross-linking conditions (lane 3). To determine whether this band contains LDH, a Western blot was carried out to detect the previously biotinylated LDH on the same membrane. In addition to the LDH monomer and dimer forms (lane 8), a $50 \mathrm{kDa}$ band was detected (lanes 6 and 7, indicated by an asterisk), that overlapped with the one detected in lanes 2 and 3. A similar cross-linking product was also detected when Sip18 and MDH were used in the assay (data not shown). These results are in agreement with a direct interaction between Sip18 and both enzymes tested under in vitro water-deficit conditions. We also detected a faint band corresponding to cross-link products between LDH and other proteins, which did not show any protective characteristics, such as RNAse A and lysozyme (data not shown) suggesting that a direct interaction with a hydrophilin is not necessarily sufficient to confer protection.

\section{DISCUSSION}

The aim of this study was to analyse the potential role of different water deficit-induced hydrophilins to protect or preserve enzymatic activities. Among the hydrophilins used, we included two dehydrins (group 2 LEA proteins), DSP16, a dehydrin that accumulates to high levels during dehydration in C. plantagineum (Piatkowski et al. 1990; Schneider et al. 1993), a plant that is able to survive water losses greater than 90\% (Gaff 1971) and, ERD10, an acidic dehydrin from $A$. thaliana, responsive to freezing and dehydration conditions (Kiyosue, Yamaguchi-Shinozaki \& Shinozaki 1994; Welin et al. 1994; Delseny et al. 2001; Seki et al. 2001). Furthermore, one representative LEA protein from each of groups 3, 4 and 6 was incorporated in this study. AtLEA76 and AtD113 correspond to groups 3 and 4 LEA proteins, respectively, from $A$. thaliana, whereas PvLEA18 is a group 6 LEA protein from $P$. vulgaris. All of them accumulate in the dry embryo and endosperm, and in vegetative tissues exposed to water deficit (Baker, Steele \& Dure 1988; Lin \& Thomashow 1992; Colmenero-Flores et al. 1999; Delseny et al. 2001; Seki et al. 2001). Finally, we also included one hydrophilin from E. coli, YCIG, and one from $S$. cerevisiae, Sip18, both responsive to osmotic shock (Miralles \& Serrano 1995, Garay-Arroyo et al. 2000).

We have established an in vitro enzymatic test based on the progressive removal of water in the absence of other perturbing factors, such as heating or freezing. In this assay, we have used MDH and $\mathrm{LDH}$, two enzymes known to be sensitive to a number of different stress conditions such as heat, lyophilization and freeze-thaw cycles (Lin \& Thomashow 1992; Dong et al. 1995; Lee 1995; Anchordoguy \& Carpenter 1996; Miller et al. 1998). Under the conditions tested, both enzymes gradually decrease their activity, albeit with slightly different kinetics (Fig. 1). Using ANS fluorescence assays with both $\mathrm{MDH}$ and $\mathrm{LDH}$, we detected a clear change in the enzyme exposure of hydrophobic regions during partial water removal, correlating with the gradual loss of enzymatic activity. In a particular range of partial water loss, both enzymes exhibit a decreased level of ANS fluorescence, suggesting that hydrophobic residues are masked under these conditions. This observation is in agreement with previous reports that show that high concentration of different osmolytes shifts the equilibrium between protein states toward the most compact conformation, and induces a decrease in the volume and compressibility of protein interior by elimination of lubricant water, which may be functionally important for the active-site region (Priev et al. 1996; Kendrick et al. 1997; Nagendra, Sukumar \& Vijayan 1998; Qu, Bolen \& Bolen 1998; Madhavarao et al. 2001). As partial water loss reaches values above $99 \%$, LDH-ANS increases its fluorescence by nearly two-fold, the same phenomenon was observed for $\mathrm{MDH}$ only after storage in the partially dehydrated state (Table 1). In both cases, a dramatic drop of activity correlates with this increase in ANS fluorescence (Fig. 1 \& Table 1), thus indicating the occurrence of structural changes leading to exposure of hydrophobic residues, as has been observed for a number of proteins (see for example Festy et al. 1998; Leydier et al. 1998).

In addition to removal of water or to the effects of low water potentials, other factors could influence the loss of enzymatic activity during the water loss assay. One such factor could be the toxicity imposed by the transient increase in ion concentrations resulting from water loss, which at $99 \%$ water loss would increase by a 100 -fold. To address this issue, we carried out experiments where Tris ${ }^{-}$, $\mathrm{K}^{+}, \mathrm{PO}_{4}^{-}$initial concentrations were modified prior to partial dehydration of LDH. Additionally, we ruled out the possibility that minimal temperature fluctuations affect enzyme activity during the assay. These changes did not modify the profile of LDH activity loss upon partial water removal (Fig. 1b) indicating that ion toxicity and temperature are not responsible for enzyme inactivation in this assay. The amount of water available upon $99 \%$ water removal corresponds to an osmolality of $2.15 \mathrm{~mol} \mathrm{~kg}^{-1}$ (equivalent to approximately -55 bars), about 10 -fold smaller than the one obtained after lyophilization and close to that present in some dried seeds (Hoekstra, Golovina \& Buitink 2001), suggesting that the osmotic potentials attained in this in vitro assay are responsible for the effects observed. It is noteworthy that the available water ( -10 to -30 bars) after the different degrees of water loss in this assay is within the range where desiccation sensitive organisms respond to a severe water stress (Hoekstra et al.2001).

The sensitivity of $\mathrm{MDH}$ and $\mathrm{LDH}$ activities to in vitro partial water loss allowed us to investigate the protective effect of different hydrophilins. The overall results show 
that during low water availability conditions (approximately -18 to -59 bars), most hydrophilins provide a level of protection of enzyme activities superior to that of BSA or trehalose, two well-known stabilizers. It is important to note that the trehalose concentration $(25 \mathrm{mM})$ required to detect protection in this assay is $10^{5}$-fold higher, on a molar basis, than that used for hydrophilins $(0.25 \mu \mathrm{M}, 1: 1$ enzyme : hydrophilin molar ratio for $\mathrm{LDH}$ ) to obtain a similar effect, suggesting different protective mechanisms and a unique mechanism of action for hydrophilins. The protective effects of BSA, trehalose and $\beta$ Lactoglobulin are in agreement with their previously described cryoprotective action (Kazuoka \& Oeda 1994). Only Sip18 showed a lower level of protection, comparable with that of BSA, suggesting that either it is not as active as other hydrophilins or its protection properties were not optimal under the conditions tested. In the case of PvLEA18, the results obtained suggest that, unlike other hydrophilins, it does not function as a protector of other proteins. Even though the protective characteristics of PvLEA18 could be restricted to mild water stress conditions, we cannot exclude a more complex scenario for its function, such as the need of post-translational modifications (phosphorylation or glycosylation) for optimal function, as previously suggested (ColmeneroFlores et al. 1999). Consistent with this last observation, the hydrophilic nature of these proteins alone would not be sufficient to confer protection, since addition of a highly hydrophilic polymer such as poly-lysine did not affect the rate of enzyme inactivation (data not shown).

In this work, we also sought to gain insight into the mechanism by which hydrophilins protect enzyme activities. As has been proposed for dehydrins (Close 1997), hydrophilins in general could stabilize cellular structures and macromolecules. Their highly hydrophilic segments could order water molecules around macromolecules thereby preventing the exposure of hydrophobic domains to the solvent. For instance, it has been shown that group 1 and 2 LEA proteins exist in equilibrium with two extended conformational states: unordered and lefthanded extended helical (PII-like) structures, suggesting that a large area for water binding constitutes the basis of their functional role (Soulages et al. 2002; 2003). Furthermore, there is evidence indicating that a group 3 LEA protein assumes an entirely unordered conformation in solution, but upon drying, the protein adopts a largely $\alpha$ helical structure (Wolkers et al. 2001). These results suggest that LEA proteins' structure can be strongly influenced by their immediate environment. Alternatively, hydrophilins could use their own polar residues to interact with the surface groups of other proteins, effectively replacing water (Close 1997; Hoekstra et al. 2001). This last possibility is more likely to occur in a more severe dehydration stage (Leydier et al. 1998). Here, we show that the decrease in ANS fluorescence observed at 93-97\% water loss (approximately -30 to -59 bars) is partially rescued upon addition of two different hydrophilins (Table 1). These results are consistent with the hypothesis that hydrophilins prevent conformational changes of target proteins that would lead to their inactivation under water limitation. In addition, using a short-range cross-linking approach, we established that an interaction between $\mathrm{MDH}$, or $\mathrm{LDH}$, with $\mathrm{Sip} 18$ occurs under the water limitation conditions reached in this assay (Fig. 4), suggesting that direct interaction between hydrophilins and target proteins is part of the protection mechanism. However, the fact that we detected cross-link products between LDH and other proteins under these conditions (RNAse A and lysozyme, data not shown), indicates that a direct interaction with a hydrophilin is not necessarily sufficient to confer protection. These findings, together with the physicochemical properties of hydrophilins lead us to suggest that these proteins preserve enzyme activities during low water availability or low osmotic potentials by a mechanism involving both organizing water molecules and a direct protein-protein interaction which would help to prevent enzyme changes in tertiary structure.

In conclusion, this study describes a method for testing the protective effects of proteins on enzyme activity during in vitro partial water loss conditions. In addition, we show for the first time that hydrophilins (including LEA proteins) are able to protect enzyme activities in vitro in a wide range of water availability levels. The use of this assay should make possible the dissection of the protective effect of LEA proteins and other hydrophilins.

\section{ACKNOWLEDGMENTS}

We are grateful to A. Gómez-Puyou, A. Darszon, E. Vierling and S. Assmann for critical reading of the manuscript, and to the Informatic Facility in the Instituto de Biotecnologia-UNAM. M-J.R. acknowledges a postdoctoral EU Research Training Grant and a fellowship of the Spanish Ministry of Education. This work was partially supported by grants from CONACyT Mexico (26242 N and I29836$\mathrm{N})$, by the CONACyT Mexico-DLR program and by a grant from the International bureau of the BMBF Germany (project MXI MD 35P).

\section{REFERENCES}

Anchordoguy T.J. \& Carpenter J.F. (1996) Polymers protect lactate dehydrogenase during freeze-drying by inhibiting dissociation in the frozen state. Archives of Biochemistry and Biophysics 332, 231-238.

Baker J., Steele C. \& Dure L.I. (1988) Sequence and characterization of 6 Lea proteins and their genes in cotton. Plant Molecular Biology 11, 277-291.

Boyle D. \& Takemoto L. (1994) Characterization of the alphagamma and alpha-beta complex: evidence for an in vivo functional role of alpha-crystallin as a molecular chaperone. Experimental Eye Research 58, 9-16.

Bray E.A. (1997) Plant responses to water deficit. Trends in Plant Science 2, 48-54.

Carpenter J.F., Prestrelski S.J. \& Arakawa T. (1993) Separation of freezing- and drying-induced denaturation of lyophilized proteins using stress-specific stabilization. Archives of Biochemistry and Biophysics 250, 505-512. 
Chang B.S. \& Mahoney R.R. (1995) Enzyme thermostabilization by bovine serum albumin and other proteins: evidence for hydrophobic interactions. Biotechnology and Applied Biochemistry 22, 203-214.

Close T.J. (1997) Dehydrins: a commonalty in the response of plants to dehydration and low temperature. Physiologia Plantarum 100, 291-296.

Colmenero-Flores J.M., Campos F., Garciarrubio A. \& Covarrubias A.A. (1997) Characterization of Phaseolus vulgaris cDNA clones responsive to water deficit: identification of a novel late embryogenesis abundant-like protein. Plant Molecular Biology 35, 393-405.

Colmenero-Flores J., Moreno L., Smith C. \& Covarrubias A.A. (1999) Pvlea18, a member of a new-late-embryogenesisabundant protein family that accumulates during water stress and in the growing regions of well-irrigated been seedlings. Plant Physiology 120, 93-103.

Danyluk J., Perron A., Houde M., Limin A., Fowler B., Benhamou N. \& Sarhan F. (1998) Accumulation of an acidic dehydrin in the vicinity of the plasma membrane during cold acclimation of wheat. The Plant Cell 10, 623-638.

Delseny M., Bies-Etheve N., Carles C., Hull G., Vicient C., Raynal M., Grellet F. \& Aspart L. (2001) Late Embryogensis Abundant (LEA) protein gene regulation during Arabidopsis seed maturation. Journal of Plant Physiology 158, 419-427.

Dong A., Prestrelski S., Allison S. \& Carpenter J. (1995) Infrared spectroscopic studies of lyophilization- and temperatureinduced protein aggregation. Journal of Pharmacological Science 84, 415-424.

Dure L.I. (1993) Plant responses to cellular dehydration during enviromental stress. In Plant Responses to Cellular Dehydration During Environmental Stress (eds T. Close \& E. Bray), pp. 91103. American Society of Plant Physiologists, Rockville, MD.

Fancy D. \& Kodadek T. (1999) Chemistry for the analysis of protein-protein interactions: rapid and efficient cross-linking triggered by long wavelength light. Proceedings of the National Academy of Sciences of the USA 96, 6020-6024.

Festy F., Lins L., Gallet X., Robert J.C. \& Thomas-Soumarmon A. (1998) 1-anilino-8-naphtalene sulfonate probes a gastric HKATPase potassium site whose access requires ionophores. Journal of Membrane Biology 165, 153-160.

Gaff D. (1971) Desiccation-tolerant flowering plants in Southern Africa. Science 174, 1033-1034.

Garay-Arroyo A., Colmenero-Flores J., Garciarrubio A. \& Covarrubias A. (2000) Highly hydrophilic proteins in prokaryotes and eukaryotes are common during conditions of water deficit. Journal of Biological Chemistry 275, 5668-5674.

Hoekstra F.A., Golovina E.A. \& Buitink J. (2001) Mechanisms of plant desiccation tolerance. Trends in Plant Science 6, 431-438.

Horwitz J. (1992) $\alpha$-crystallin can function as molecular chaperone. Proceedings of the National Academy of Sciences of the USA 89, 10449-10453.

Imai R., Chang L., Ohta A., Bray E. \& Tagaki M. (1996) A Lea class gene of tomato confers salt and freezing tolerance when expressed in Saccharomyces cerevisiae. Gene 170, 243-248.

Ingram J. \& Bartels D. (1996) The molecular basis of dehydration tolerance in plants. Annual Review of Plant Physiology and Plant Molecular Biology 47, 377-403.

Ismail A.M., Hall A.E. \& Close T.J. (1999) Allelic variation of a dehydrin gene cosegregates with chilling tolerance during seedling emergence. Proceedings of the National Academy of Sciences of the USA 96, 13566-13570.

Jepson S.G. \& Close T.J. (1995) Purification of a maize dehydrin protein expressed in Escherichia coli. Protein Expression and Purification 6, 632-636.

Kazuoka T. \& Oeda K. (1994) Purification and characterization of
COR85-oligomeric complex from cold-acclimated spinach. Plant and Cell Physiology 35, 601-611.

Kendrick B.S., Chang B.S., Arakawa T., Peterson B., Randolph T.W., Manning M.C. \& Carpenter J.F. (1997) Preferential exclusion of sucrose from recombinant interleukin-1 receptor antagonist: role in restricted conformational mobility and compaction of native state. Proceedings of the National Academy of Sciences of the USA 94, 11917-11922.

Kiyosue T., Yamaguchi-Shinozaki K. \& Shinozaki K. (1994) Characterization of two cDNAs (ERD10 and ERD14) corresponding to genes that respond rapidly to dehydration stress in Arabidopsis thaliana. Plant and Cell Physiology 35, 225-231.

Lee G.J. (1995) Assaying porteins for molecular chaperone activity. Methods in Cell Biology 50, 325-334.

Leydier C., Clottes E., Couthon F., Marcillat O., Ebel C. \& Vial C. (1998) Evidence for kinetic intermediate states during the refolding of $\mathrm{GdnHCl}$-denatured MM-creatine kinase. Characterization of a trapped monomeric species. Biochemistry 37, 17579-17589.

Lin C. \& Thomashow M.F. (1992) A cold-regulated Arabidopsis gene encodes a polypeptide having potent cryoprotective activity. Biochemistry and Biophysics Research Communications 183, 1103-1108.

Madhavarao C.N., Sauna Z.E., Srivastava A. \& Sitaramam V. (2001) Osmotic perturbations induce differential movements in the core and periphery of proteins, membranes and micelles. Biophysical Chemistry 90, 233-248.

Miller D.P., Anderson R.E. \& de Pablo T.J. (1998) Stabilization of lactate dehydrogenase following freeze thawing and vacuumdrying in the presence of trehalose and borate. Pharmacological Research 15, 1215-1221.

Miralles V.J. \& Serrano R. (1995) A genomic locus in Saccharomyces cerevisiae with four genes up-regulated by osmotic stress. Molecular Microbiology 17, 653-662.

Nagendra H.G., Sukumar N. \& Vijayan M. (1998) Role of water in plasticity of proteins: the crystal structures of lysozyme at very low levels of hydration. Proteins: Structure, Function and Genetics 32, 229-240.

Piatkowski D., Schneider K., Salamini F. \& Bartels D. (1990) Characterization of five abscisic acid-responsive cDNA clones isolated from the desiccation tolerant plant Craterostigma plantagineum and their relationship to other water-stress genes. Plant Physiology 94, 1682-1688.

Posas F., Chambersi J.R., Heymani J.A., Hoeffleri J.P., de Nadal E. \& Ariño J. (2000) The transcriptional response of yeast to saline stress. Journal of Biological Chemistry 275, 17249-17255.

Priev A., Almagor A., Yedgar S. \& Gavish B. (1996) Glycerol decreases the volume and compressibility of protein interior. Biochemistry 35, 2061-2066.

Qu Y., Bolen C.L. \& Bolen D.W. (1998) Osmolyte-driven contraction of a random coil protein. Proceedings of the National Academy of Sciences of the USA 95, 9268-9273.

Rinne P.L.H., Kaikuranta P.L.M., van der Plas L.H.W. \& van der Schoot C. (1999) Dehydrins in cold-acclimated apices of birch (Betula pubescens Ehrh.): production, localization and potential role in rescuing enzyme function during dehydration. Planta 209, 377-388.

Schneider K., Wells B., Schmelzer E., Salamini F. \& Bartels D. (1993) Desiccation leads to rapid accumulation of both cytoplasmic an chloroplastic proteins in the resurrection plant $\mathrm{Cra}$ terostigma plantagineum Hochst. Planta 189, 120-131.

Seki M., Narusaka M., Abe H., Kasuga M., Yamaguchi-Shinozaki K., Carninci P., Hayashizaki Y. \& Shinozaki K. (2001) Monitoring the expression pattern of 1300 Arabidopsis genes under drought and cold stresses by using a full-length cDNA microarray. The Plant Cell 13, 61-72. 
Soulages J.L., Kim K., Walters C. \& Cushman J.C. (2002) Temperature-induced extended helix/random coil transitions in a group 1 late embryogenesis-abundant protein from soybean. Plant Physiology 128, 822-832.

Soulages J.L., Kim K., Arrese E.L., Walters C. \& Cushman J.C. (2003) Conformation of a group 2 late embryogenesis abundant protein from soybean. Evidence of poly (1-proline) -type II structure. Plant Physiology 131, 963-975.

Suarez-Varela A., Sandez-Macho M.I. \& Minones J. (1992) Spectrofluorimetric study of the binding of 1-anilinonaphthalene-8sulfonate to bovine serum albumin. Journal of Pharmacological Sciences 81, 842 ñ, 844.

Swire-Clark G.A. \& MarcotteW.R. Jr (1999) The wheat LEA protein Em functions as an osmoprotective molecule in Saccharomyces cerevisiae. Plant Molecular Biology 39, 117-128.

Tamiya T., Okahashi N., Sakuma R., Aoyama T., Akahane T. \& Matsumoto Y. (1985) Freeze denaturation of enzymes and its prevention with additives. Cryobiology 22, 446-456.

Welin B.V., Olsson A., Nylander M. \& Palva E. T. (1994) Characterization and differential expression of dhn/lea/rab-like genes during cold acclimation and drought stress in Arabidopsis thaliana. Plant Molecular Biology 26, 131-144.

Wolkers W.F., McCready S., Brandt W.F., Lindsay G.G. \& Hoekstra F.A. (2001) Isolation and characterization of a D-7 LEA protein from pollen that stabilizes glasses in vitro. Biochemica et Biophysica Acta 1544, 196-206.

Xu D., Duan X., Wang B., Hong B., Ho T.-D. \& Wu R. (1996) Expression of a late embryogenesis abundant protein gene, $H V A 1$, from barley confers tolerance to water deficit and salt stress in transgenic rice. Plant Physiology 110, 249-257.

Yale J. \& Bohnert H.J. (2001) Transcript expression in Saccharomyces cerevisiae at high salinity. Journal of Biological Chemistry 276, 15996-16007.

Zhang L., Ohta A., Takagi M. \& Imai R. (2000) Expression of plant group 2 and group 3 lea genes in Sacharomyces cerevisiae revealed functional divergence among LEA proteins. Journal of Biochemistry 127, 611-616.

Received 23 May 2004; received in revised form 29 November 2004; accepted for publication 11 December 2004 